\title{
The Effect on Electrochemical Properties of Co on Al-Si-Fe Alloys for Anode Material of Lithium-Ion Batteries
}

\author{
S. Yildiz, E. Albayrak, and O. Uzun
}

\begin{abstract}
Due to its high theoretical capacity of $4200 \mathrm{~mA} \mathrm{~h} \mathrm{~g}^{-1}$, silicon has great interest for the alternative anode material for lithium-ion batteries. However, insufficient cycle performance come from a large volumetric change during cycling, seriously restrict its practical use. Nano-structured alloys included silicon have potential for anode materials such as Al-Si alloys. The effect of Co on high energy ball milled $\mathrm{Al}-\mathrm{Si}-\mathrm{Fe}$ alloy in the condition of repeated charging and discharging capacity measurement has been demonstrated. Improved cycle capacity of alloy has been obtained by Co addition.
\end{abstract}

Index Terms-Li-Ion Batteries, Al-Si Alloys, High Energy Ball Milling.

\section{INTRODUCTION}

$\mathrm{Si}$ and $\mathrm{Al}$ are promising material because of theoretical specific capacity. Each $\mathrm{Si}$ atom litheated with $4.4 \mathrm{Li}$ atoms [1, 2] and each $\mathrm{Al}$ atom litheated $2.25 \mathrm{Li}$ atoms [3]. However, the commercial application of $\mathrm{Si}$ is suppressed by the large volume expansion (>\%300) during litheation bring out mechanical stress. This enormous stress give rise to pulverization and happened to decreasing interface between current collector and active anode material. This situation limited cycle performance.

To achieve high cycle performance, AlSi alloy have been extensively investigated [4-7]. In this work, we investigated Co effect on high energy ball milled AlSiFe alloy as an anode active material.

\section{II.EXPERIMENTAL}

Pure Al powder (\%99.999 with average particle size 106 to $250 \mu \mathrm{m})$, Si scrap (\%99.99 with average particle size 3 to 5 $\mu \mathrm{m})$, and Fe powder (\%99.99 with average particle size 10 to $15 \mu \mathrm{m})$ were used synthesize the $\mathrm{Al}_{75-\mathrm{x}} \mathrm{Si}_{20} \mathrm{Fe}_{5}-\mathrm{Co}_{\mathrm{x}}(\mathrm{x}=0,1,5$ wt $\%$ ) alloys. High-energy milling process was applied 10 minutes in Ar atmosphere at 800 rpm (Planetary ball mill,

Manuscript received November 5, 2015. This work was supported in part by the Scientific Research Projects Commission of Ahi Evran University (Project No: PYO-MUH.4001.14.015) and Scientific and Technological Research Council of Turkey (TUBITAK) (Project No:110M517).

S. Yildiz is with the Department of Metallurgical and Materials Engineering, Ahi Evran University, Kırşehir, Turkey

E. Albayrak is with the Department of Metallurgical and Materials Engineering, Ahi Evran University, Kırşehir, Turkey

Metallurgical and Materials Engineering, Bulent Ecevit University, Zonguldak, Turkey
P100, TMC) with stainless steel balls and vessel [8]. The weight ratio of ball-to-powder was selected 20:1, with stearic acid added (10 wt pct of mixed powder) to moderate the cold-welding process.

The powders mixed homogeneously with carbon black and the mixture was blended with polyvinylidene fluoride (PVDF) dissolved in N-methylpyrrolidinone (NMP). The mass ratio of the powders, carbon black, and PVDF was 84:8:8. The slurry stirred at room temperature 12 hours and then was coated on a copper foil using a doctor blade and dried at $373 \mathrm{~K}$ in a vacuum oven for $12 \mathrm{~h}$ to remove the NMP. Batteries were assembled in an $\mathrm{Ar}$ atmosphere glove box (Innovative Technology, I-Lab 4GB). The electrochemical behaviors were tested using two-electrode Swagelok cells which were composed of alloy electrode as the positive electrode, a pure lithium foil as the counter electrode, Celegard 2400 as the separator and electrolyte. The electrolyte is the mixture of $1 \mathrm{M}$. LiPF6 solution in ethylene carbonate/diethyl carbonate (EC:DEC=1:1, v/v).

The electrochemical measurement was performed on a battery analyzer (MTI BST8-3) using a constant current density of $0.05 \mathrm{~A} \mathrm{g-1}$ between two cut-off voltages of 0.1 and 3 $\mathrm{V}$. The structures of alloys were analyzed by the XRD, and the lithiated anodes surface morphology after cycles was observed using a Scanning Electron Microscope (FE-SEM, FEI, Quanta FEG 450).

\section{RESUlT AND DISCUSSION}

Effect of Co alloying additive on XRD pattern of Al-20Si-5Fe alloys is demonstrated in Figure 3. According to figure, any intermetallic phases were detected in any of the alloys. It can be mentioned two possible reasons. One of them is prevention of intermetallic phase formation such as $\beta$-Al5FeSi by insufficiency of X-ray diffraction in detecting phases with low volume concentrations below 5 vol pct. [9] and the other is inability of milling time to form any intermetallic phases. [10]. Very long counting rates can be necessary to detect the presence any sizeable intermetallic signals but also the additional phases can be engaged in the any $\alpha$-phases. 


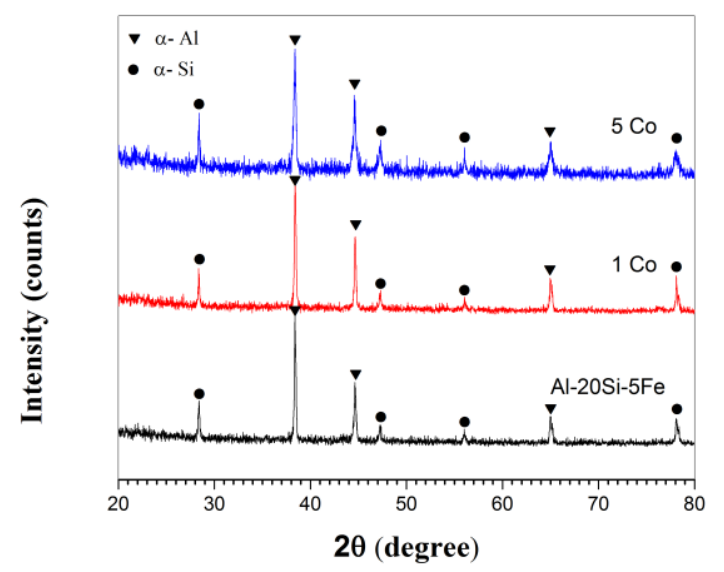

Fig. 1. X-Ray Diffraction Patterns of Al-20Si-5Fe Alloys.

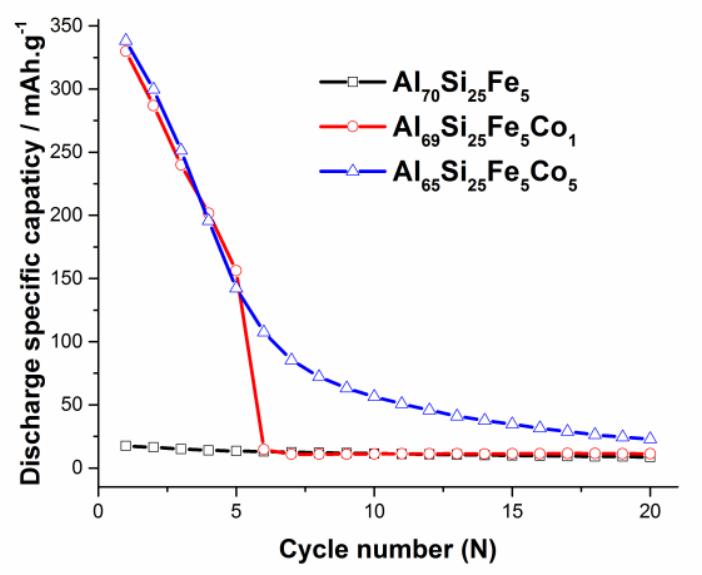

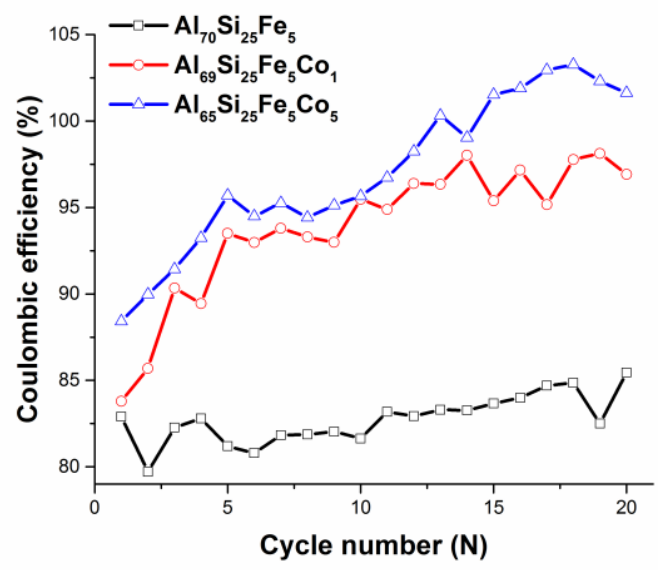

Fig. 3. The Effect of Co Content on Coulombic Efficiency of Al-20Si-5Fe Alloys Fabricated By High Energy Ball Milling.

Electrochemical properties of the alloys have shown in Figures 2 and 3. As shown in the Figure 2, cycle performance and capacity of the batteries have improved by Co. Similarly, in Figure 3 coulombic efficiency has improved by Co. Rapid decreasing in the capacity with increasing cycle numbers comes from pulverization and crack growth in active material during lithiation/delithiation. After twenty cycles, observed crack morphologies of $\mathrm{Al}_{75-\mathrm{x}} \mathrm{Si}_{20} \mathrm{Fe}_{5}-\mathrm{Co}_{\mathrm{x}}$ anodes are shown in Figure 4. Several times more cracks appear in $\mathrm{Al}_{69} \mathrm{Si}_{20} \mathrm{Fe}_{5^{-}} \mathrm{Co}_{1}$ anode. This situation can explain the rapid decreasing of cycle performance of $\mathrm{Al}_{74} \mathrm{Si}_{20} \mathrm{Fe}_{5}-\mathrm{Co}_{1}$ anode.

Fig. 2. The Effect of Co Content on Cycle Performance of Al-20Si-5Fe Alloys Fabricated By High Energy Ball Milling.

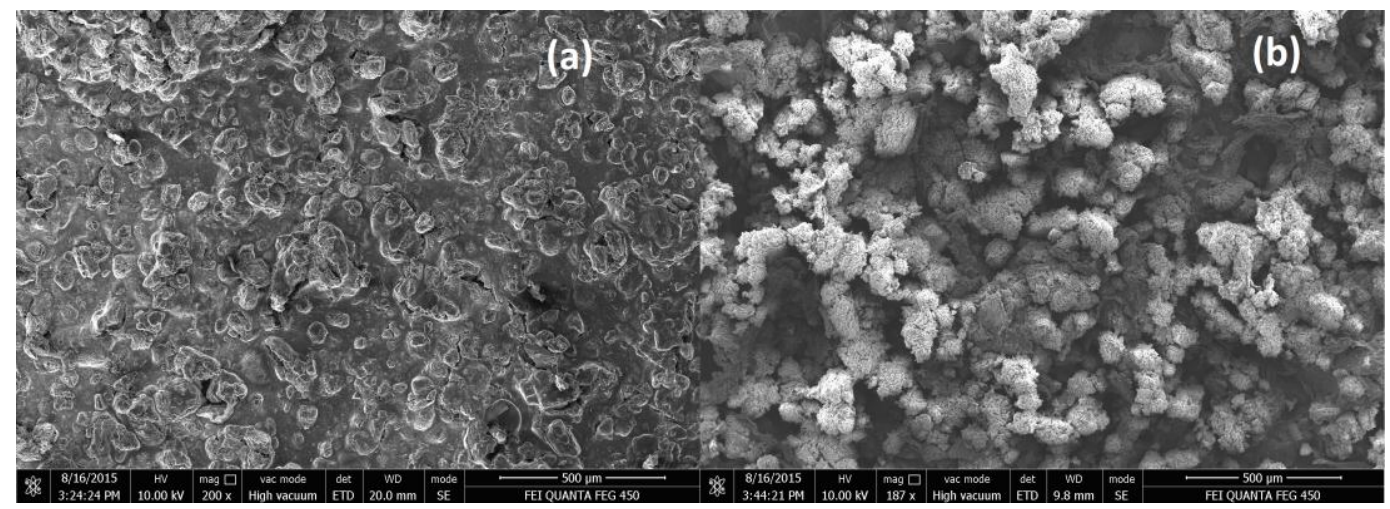

Fig. 4. Crack Morphologies of (A) $\mathrm{Al}_{74} \mathrm{Si}_{20} \mathrm{Fe}_{5^{-}} \mathrm{Co}_{1}$ And (B) $\mathrm{Al}_{65} \mathrm{Si}_{20} \mathrm{Fe}_{5^{-}} \mathrm{Co}$ Anodes.

\section{CONCLUSION}

Electrochemical performance of high energy ball milled $\mathrm{Al}_{75-\mathrm{x}} \mathrm{Si}_{20} \mathrm{Fe}_{5}-\mathrm{Co}_{\mathrm{x}}(\mathrm{x}=0,1,5)$ anodes have been presented. Crack morphology has been demonstrated. Co content improved capacity and cycle performance of the batteries.

\section{REFERENCES}

[1] B. A. Boukamp, G. C. Lesh, and R. A. Huggins, "All-Solid Lithium Electrodes with Mixed-Conductor Matrix," J. Electrochem. Soc., vol. 128 , no. 4, pp. 725-729, Nov. 1981. http://dx.doi.org/10.1149/1.2127495

[2] S. Ohara, J. Suzuki, K. Sekine, and T. Takamura, "A thin film silicon anode for Li-ion batteries having a very large specific capacity and long cycle life," J. Power Sources, vol. 136, pp. 303-306, Oct. 2004. http://dx.doi.org/10.1016/j.jpowsour.2004.03.014 
[3] A. J. McAlister, "The Al-Li (Aluminum-Lithium) system" Bull. Alloy Phase Diagrams, vol. 3, no. 2, pp. 177-183 1982. http://dx.doi.org/10.1007/BF02892377

[4] K. M. Lee, Y. S. Lee, Y. W. Kim, Y. K. Sun, and S. M. Lee, "Electrochemical characterization of $\mathrm{Ti}-\mathrm{Si}$ and $\mathrm{Ti}-\mathrm{Si}-\mathrm{Al}$ alloy anodes for Li-ion batteries produced by mechanical ball milling," J. Alloys Compd., vol. 472, no. 1-2, pp. 461-465, Mar. 2009. http://dx.doi.org/10.1016/j.jallcom.2008.04.102

[5] L. B. Chen, J. Y. Xie, H. C. Yu, and T. H. Wang, "Si-Al thin film anode material with superior cycle performance and rate capability for lithium ion batteries," Electrochim. Acta, vol. 53, no. 28, pp. 8149-8153, Nov. 2008.

http://dx.doi.org/10.1016/j.electacta.2008.06.025

[6] Z. X Chen, J. F. Qian, X. P. Ai, Y. L. Cao, and H. X. Yang, "Electrochemical performances of Al-based composites as anode materials for Li-ion batteries," Electrochim. Acta, vol. 54, no. 16, pp. 4118-4122 June 2009. http://dx.doi.org/10.1016/j.electacta.2009.02.049

[7] Z. B. Sun, X. D. Wang, X. P. Li, M. S. Zhao, Y. Li, Y. M. Zhu, and X. P. Song, "Electrochemical properties of melt-spun Al-Si-Mn alloy anodes for lithium-ion batteries," Journal of Power Sources, vol. 182, no. 1, pp. 353-358, July 2008.

http://dx.doi.org/10.1016/j.jpowsour.2008.03.053

[8] M. F. Kilicaslan, O. Uzun, F. Yilmaz, and S. Çağlar, "Effect of Different Production Methods on the Mechanical and Microstructural Properties of Hypereutectic Al-Si Alloys," Metall. Mater. Trans. B, vol. 45, no. 5, pp. 1865-1873, June 2014.

http://dx.doi.org/10.1007/s11663-014-0098-8

[9] M. Rajabi, M. Vahidi, A. Simchi, and P. Davami, "Effect of rapid solidifiation on the microstructure and mechanical properties of hot-pressed Al-20Si-5Fe alloys," Materials Characterization, vol. 60, no. 11, pp. 1370-1381, Nov. 2009. http://dx.doi.org/10.1016/j.matchar.2009.06.014

[10] W. K. Kang, F. Yilmaz, H. S. Kim, J. M. Koo, and S. J. Hong, "Fabrication of Al-20 wt\%Si powder using scrap Si by ultra high-energy milling process," J. Alloys Compd., vol. 536S, pp. S45-49, Sep. 2012.

http://dx.doi.org/10.1016/j.jallcom.2012.01.106 